\title{
Antithrombotic Utilization Evaluation in Patients Suffering from Deep Vein Thrombosis at a Tertiary Care Teaching Hospital
}

\author{
Chandresh B. Dumatar, Sandip S. Jadav, Aashutosh J. Patel \\ Department of Pharmacology, B. J. Medical College, Ahmedabad, Gujarat, INDIA.
}

\begin{abstract}
Objective: To evaluate the usage pattern of antithrombotic in patients suffering from deep vein thrombosis (DVT) in a tertiary care teaching hospital. Methods: It was an observational, prospective and single centre study carried out over period of 18 months among the indoor patients suffering from DVT in department of Surgery, Orthopedics and Neurosurgery at a tertiary care teaching hospital. Results: Out of 26,687 indoor patients assessed for eligibility, only $32(0.12 \%)$ patients were of DVT. Out of 32 patients of DVT, all the patients were prescribed anticoagulant drug whereas, 4 patients were prescribed both antiplatelet and anticoagulant. Only 2 patients were given aspirin as a single drug. No modification of antiplatelet therapy was observed. None of DVT patients had contraindication to use of anticoagulants. Only 4 patients developed bleeding during follow up. Conclusion: DVT treatment is very important and antithrombotic therapy is mainstay of treatment among patients of DVT. All patients of DVT received adequate antithrombotic therapy. Warfarin was most commonly
\end{abstract}

used anticoagulant for DVT treatment.

Key words: Antithrombotic, Deep vein thrombosis, Drug utilization.

Key message: Warfarin and enoxaparin are most commonly prescribed anticoagulants for treatment of DVT. Risk and benefits should be considered in the decision for antithrombotic treatment with anticoagulants. With proper antithrombotic guidelines, morbidity and mortality due to DVT or complications of DVT can be prevented to improve quality of life (QOL).

\section{Correspondence:}

Dr. Sandip S. Jadav, Tutor, Department of Pharmacology, B. J. Medical College, Ahmedabad, Gujarat, INDIA.

Phone: 9724252449

Email: Sandip09jadu@gmail.com

DOI: 10.5530/jyp.2018.10.19

\section{INTRODUCTION}

Deep vein thrombosis (DVT) and pulmonary embolism (PE) are preventable causes of death and high morbidity disorders which affects both medical and surgical patients. ${ }^{1,2}$ It was believed that development of VTE in the Asian population was less than in the Western population but such theory has been disproved by recent studies. ${ }^{3,4}$ As soon as the diagnosis of DVT is confirmed clinically or by laboratory investigations, antithrombotic medications are started because anticoagulant drugs with a rapid onset of action are needed to prevent further complications. ${ }^{5}$ Standard of care for DVT treatment is heparin and studies have proven that it significantly reduce the risk of PE, as well as recurrent DVT. ${ }^{6,7}$ UFH and LMWH both classes of drugs have comparable efficacy and safety in treatment of DVT and also data suggest that both are safe. ${ }^{8,9}$ However, anticoagulant use with inappropriate dosage in DVT may lead to increased risk of bleeding and other complications. In asymptomatic DVT patients routine screening is difficult and also not cost effective, compare to prophylactic treatment which is very effective. ${ }^{10}$ Many VTE prophylaxis guidelines have been developed including the American College of Chest Physicians (ACCP) and they are very useful to assess risk factor of DVT. ${ }^{10}$ Untreated DVT can further lead to recurrent VTE $\&$ PE. The need for anticoagulation in patients of DVT is variable depending on the basis of age, co-morbidities and risk factors. Enoxaparin is the drug of choice for acute cases whereas warfarin is drug of choice in case of maintenance therapy and also for prophylaxis. ${ }^{11}$

Very few studies are available about usefulness of DVT prophylaxis in the medically ill patient. Variations in drug use and to support interventions which improve patient outcomes are objectives of drug utilization evaluation (DUE). Drug use indicators are intended to measure specific aspects of health providers and drug use in a hospital or health center. ${ }^{12}$ DUE indicators also reflects the status of an essential requirement of the given health care services. ${ }^{13}$ Due to the double edge sword nature of anticoagulation and various treatment guidelines availability for DVT, we decided to carry out a drug utilization evaluation of antithrombotics in patients suffering from DVT at Government teaching hospital.

\section{MATERIALS AND METHODS}

The study was observational, prospective and single centre conducted to know utilization pattern of DVT carried out among the indoor patients in department of Surgery, Orthopaedics and Neurosurgery at Civil Hospital, a tertiary care Government teaching hospital over period of 18 months. Patients of either gender above 25 years of age, operated for major elective surgery and who are bedridden hospitalized for more than 3 days in ward were included in study. Ambulatory hospitalized patients for more than 3 days in ward and who are operated for emergency or minor surgical procedure were excluded from study.

For every patient, data was recorded in a pre-designed case record form which included data like demographics such as age, gender, reason for hospitalization, details of antithrombotics used, duration of hospital stay and monitoring data (INR) at time of enrollment and till the time of discharge. During the study patients were monitored for modification in antithrombotic therapy and other complications due to antithrombotic therapy. The study was approved by Institutional Ethics Committee, Civil hospital. 


\section{Statistical analysis}

The data collected was compiled, entered and analyzed in Microsoft Excel spreadsheet 2007 and Graph pad version 4. The results are expressed in terms of numbers and percentage.

\section{RESULTS}

Out of 26,687 patients only 32 (16.32\%) patients were of DVT. General characteristics and reasons for hospitalization of patients are given in Table 1. Maximum number of patients belonged to 41-70 years of age group ( $n=23)$. Out of 32 patients of DVT, 8 patients had prior surgical intervention for one or other reasons. 6 patients had history of prior surgery for varicose vein. Out of 32 patients, 9 patients had history of smoking and hypertension whereas 6 patients were smokers without any other risk factor. Out of 32 patients of DVT, 3 patients were admitted in surgery department for intense pain and difficulty in walking due to DVT but thrombectomy was not done in any patient. In all 32 patients of DVT, details of location and extent of thrombus is given in Figure 1.

In all DVT patients, INR was within normal range (1.5-2.0) in 26 $(81.25 \%)$ newly diagnosed patients while $6(18.75 \%)$ previously diagnosed patients with DVT had increased INR (average 2.3). Out of 32 patients DVT, 26 (81.25\%) patients were newly diagnosed, 6 (18.75\%) patients were diagnosed before enrollment in the study. Among this 6 patients, 4 patients were diagnosed within last 1 month whereas 2 patients were diagnosed within 3 months (4 patients had $1^{\text {st }}$ follow up and 2 patients had $2^{\text {nd }}$ follow-up). The major risk factors before hospitalization and during hospital stay are presented in Table 2.

Details of antithrombotic prescribed among DVT patients are given in Table 3. All the patients were prescribed anticoagulant drug whereas, 4 patients were prescribed both antiplatelet and anticoagulant. Out of 32 patients, 26 newly diagnosed patients were given enoxaparin along with warfarin. Out of 26 newly diagnosed patients, 21 patients received $5 \mathrm{mg}$ warfarin and 5 patients received $2 \mathrm{mg}$ warfarin along with enoxaparin from day 2 or day 3. Enoxaparin was stopped after 5 days. No

\begin{tabular}{|c|c|}
\hline & Patients of DVT $(n=32)$ \\
\hline Age (years) $[$ mean $\pm S D]$ & $59.42 \pm 9.05$ \\
\hline \multicolumn{2}{|l|}{ Sex - no. of patients (\%) } \\
\hline - $\quad$ Male & $21 / 32(65.62 \%)$ \\
\hline - $\quad$ Female & $11 / 32(34.38 \%)$ \\
\hline Duration of hospital stay (days) Mean (range) & $6(5-7)$ \\
\hline \multicolumn{2}{|l|}{ Reasons for hospitalization - no. of patients (\%) } \\
\hline Hip replacement & - \\
\hline Hip fracture & - \\
\hline Ankle/knee fracture & - \\
\hline Orthopaedic trauma & - \\
\hline Gastric surgery & - \\
\hline Vascular surgery & 8 \\
\hline Spine surgery & - \\
\hline Malignancy & - \\
\hline Accidental trauma & - \\
\hline Under observation in surgical ward & 10 \\
\hline Other surgery & 14 \\
\hline
\end{tabular}

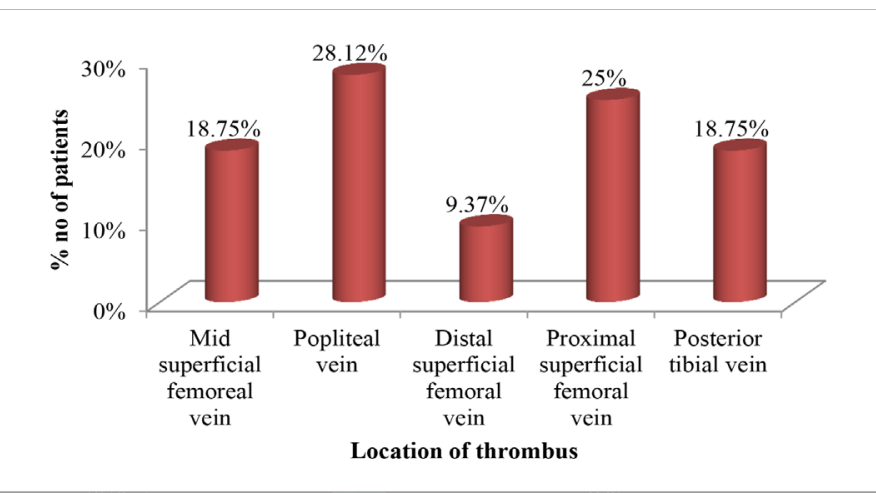

Figure 1: Location of thrombus in patients of DVT $(n=32)$

\begin{tabular}{cc} 
Table 2: Risk factors for DVT $(\mathbf{n}=\mathbf{3 2})$. & \\
\hline Risk factors & Patients of DVT $(\mathbf{n}=\mathbf{3 2})$ \\
\hline Before hospital admission & - no. of patients $(\%)$ \\
History of DVT & 01 \\
Obesity & 01 \\
Varicose vein & 03 \\
Any thrombophilia & 01 \\
Use of OCPs & 08
\end{tabular}

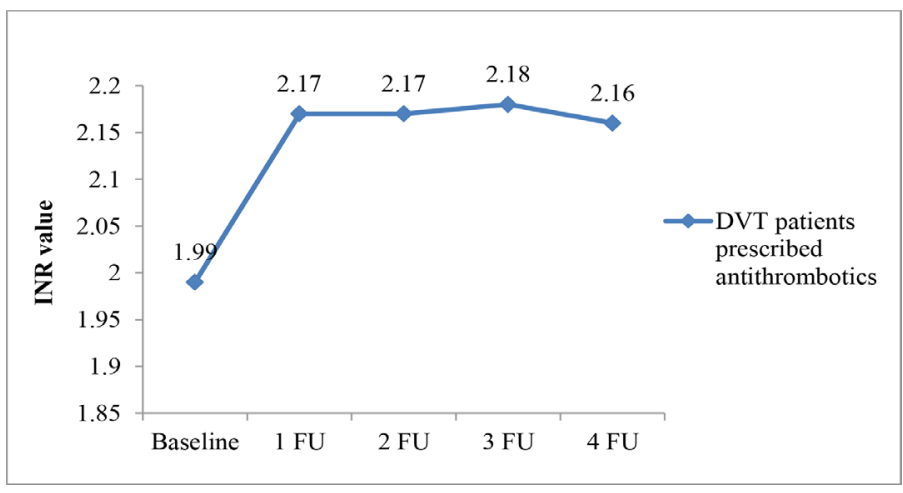

Figure 2: Mean INR value changes from baseline to end of study in patients of DVT $(n=32)$

modification of antiplatelet therapy was observed. Patients who were prescribed anticoagulant (warfarin) reduction in dose of warfarin was observed (from $5 \mathrm{mg}$ to $2 \mathrm{mg}$ ) in 2 patients after $2^{\text {nd }}$ follow-up and in 7 patients after $3^{\text {rd }}$ follow-up. None of DVT patients had contraindication to use of anticoagulants. All patients were prescribed anticoagulant warfarin $(\mathrm{n}=32)$ and mean INR value was $1.98 \pm 0.14$ with range from 1.89 to 2.5 . Mean INR value changes from baseline to end of study in patients of DVT are shown in Figure 2.

All the antithrombotic drugs (warfarin, enoxaparin, heparin and aspirin) were included in National Essential drug list of India (2011), Gujarat Essential drug list (2014-15) and WHO Essential Medicine list $\left(18^{\text {th }}\right.$ list, 
Dumatar et al:: Antithrombotic utilization in patients suffering from deep vein thrombosis

\begin{tabular}{ccccc}
\multicolumn{6}{l}{ Table 3: Usage pattern of anticoagulant and antiplatelet drugs of DVT $\mathbf{( n = 3 2 ) .}$} \\
\hline Drug & Dose & Frequency & $\begin{array}{c}\text { Route of } \\
\text { administration }\end{array}$ & No. of patients \\
\hline Enoxaparin $^{*}$ & $0.6 \mathrm{mg}$ & 1 injection for 5 days & Subcutaneous & 32 \\
Warfarin & $2 \mathrm{mg}$ & 1 tablet daily & Oral & 07 \\
Warfarin + Aspirin & $5 \mathrm{mg}$ & 1 tablet daily & Oral & 21 \\
\hline
\end{tabular}

${ }^{*}$ Enoxaparin was given in all patients for 5 days followed by oral antithrombotics (warfarin and aspirin)

April 2013). Only 3 different antithrombotic drugs were used [warfarin, enoxaparin (anticoagulant) and aspirin (antiplatelet)] in DVT patients. Only warfarin (anticoagulant) accounted for $100 \%$ of the total antithrombotic use.

\section{Outcome and follow up}

None of the patients developed stroke, systemic embolism, pulmonary embolism or death during follow up. Only 4 patients developed bleeding during follow up.

\section{DISCUSSION}

Present study included the patients of varying ages (25-70 years) with mean age $46.19 \pm 12.57$ years and maximum number of patients belonged to age group 40-70 years. However, high mean age was 70 years with the range from 58-79 years was reported in one study..$^{14}$ Majority of showed that occurrence of DVT was more in patients aged 50 years or more. ${ }^{15} \mathrm{In}$ our study, mean age was 46 years. Reason may be that we have enrolled patients from 25-70, whereas in other studies, it was above 40 years. Patients from surgery department were more in our study as well as other study. The reason could be longer duration of hospitalization and immobilization in surgery department as compared with other departments. Prevalence of proximal lower limb venous thrombosis was higher (57.36\%) than distal lower limb. Consistent with that in another study, incidence of proximal lower limb thrombosis was higher $(60.70 \%)$ than distal lower limb. ${ }^{16}$ This shows that incidence of proximal lower limb thrombosis are higher worldwide. ${ }^{14}$ In present study, major risk factor in DVT patients was use of OCPs (25\%) followed by presence of varicose vein $(9.38 \%)$. In our study, use of OCPs was the major risk factor because almost all the women enrolled in the study gave history of use of OCPs. Use of OCPs is predisposing condition for development of DVT. ${ }^{17}$

In present study, all patients of DVT $(n=32)$ were given anticoagulant drugs, $12.5 \%(n=4)$ patients were given antiplatelets in combination of anticoagulants. Antiplatelets alone were not prescribed in patients of DVT. Enoxaparin was given once daily whereas in other study conducted at Denmark, enoxaparin was given twice daily for specific thromboprophylaxis of knee joint replacement. ${ }^{18}$ In our study, 95\% patients were managed by enoxaparin and heparin alone. This is similar with another study done in India in which, $98 \%$ patients were managed by anti-coagulants mostly LMWH alone. ${ }^{14}$ This was attributed to better acceptance and ease of using LMWH. ${ }^{19}$

In our study only 3 different anti-thrombotic were used. The reasons for this may be poor availability and higher cost of NOACs. Also NOACs have some limitations like lack of anti-dote, long term safety not established and lack of validated tests to monitor anti-coagulant effect ${ }^{20}$ but for warfarin, anti-coagulant monitoring is validated, antidote is available and long term safety is well established. We observed that antiplatelet and anticoagulant were used exclusively by oral routes. Reason may be that antithrombotic drugs were not available in different formulations.
Also parenteral therapy requires hospitalization and monitoring of therapy which increases cost in condition like DVT.

In patients whom no undesired adverse event was observed, no change in dose of warfarin was observed in patients even after $2^{\text {nd }}$ or $3^{\text {rd }}$ follow-up. Those who developed bleeding or any other adverse event $(n=9)$, reduction in dose from $5 \mathrm{mg}$ to $2 \mathrm{mg}$ was done at $1^{\text {st }}$ follow-up, to decrease the risk of bleeding.

Increase in INR value among 6 patients was observed who were already on anticoagulant therapy. Moreover, this may explain the difficulty of managing patients on anticoagulant treatment. It is important to monitor anticoagulation status but it is not possible for all patients due to high cost of monitoring, need for frequent monitoring and dose adjustments. It is well known that anti-coagulants have a narrow therapeutic range and exhibit wide variation in response, which may lead to toxicity and drug discontinuation.

In present study, none of the patients developed recurrent DVT, post-thrombotic syndrome, pulmonary embolism, systemic embolism or death due to DVT. In contrast to our study, one study showed mortality due to PE was high $(49.5 \%){ }^{21}$ This may be, because present study had very small sample size and short study period as compared to other studies. The diagnosis of post-thrombotic syndrome can be made on basis of clinical features which may mimic acute recurrence of DVT and confirmed by MRI. Recurrent DVT occurs in about $20 \%$ of patients at 5 years and $30 \%$ after 10 years of follow-up. ${ }^{22}$ In present study, it was not possible to follow the patient for long duration. A post-phlebitic syndrome occurs in about $25 \%$ of patients with DVT and almost $30 \%$ of patients develop post-phlebitic syndrome after 20 years of follow-up. ${ }^{23}$ In present study, patients of DVT were advised to use graduated compression stockings and pneumatic compression devices but none of the patients used it. Both ambulation and exercises involving foot extension (improves venous flow) should be encouraged. Pneumatic compression devices also reduces venous stasis and are effective in reducing the risk of post-operative DVT. $^{24}$

In present study, major adverse event was injection site pain (7\%) which occurred due to injectable anti-coagulant enoxaparin which may cause hematoma formation. Major bleeding event was observed in $2 \%$ patients in our study which was similar to another study (1.2\%) done at London. ${ }^{15}$ Reason could be concomitant use of anti-platelet along with anti-coagulant was higher in our study whereas in other studies, only anti-coagulant were used alone.

Present study had some limitations but has drawn some important clinical implications. One of the limitations was small sample size and study duration was short so we were not able to determine efficacy of antithrombotic therapy in prevention of recurrence of DVT. It would be worthwhile to follow these patients for at least 5-8 years.

Despite of such limitations, some important clinical implications drawn from our results like prevalence of DVT was similar to Western countries published literature. More than $75 \%$ of drugs were supplied from hospital 
store. So, if newer anticoagulants drugs would be available in hospital store, their usefulness could be evaluated. Patients contraindicated for anticoagulation did not receive any other surgical or other treatment modalities for treatment of DVT. Majority of patients were evaluated by INR for risk of bleeding which shows good awareness regarding DVT at present institution.

\section{CONCLUSION}

Warfarin and enoxaparin are most commonly used antithrombotics for treatment of DVT. All DVT patients received adequate antithrombotic therapy. Patient characteristics, concomitant therapy and clinician's own experience are main factors to decide anticoagulant therapy. Also INR was done regularly to monitor antithrombotic therapy. Antithrombotic drugs were included in State as well as National essential Medicine list. Furthermore, it is also recommended to have a local thromboprophylaxis and treatment guideline for management of DVT patients.

\section{ABBREVIATION USED}

DVT: Deep vein thrombosis; NOACs: Newer oral anticoagulants; INR: International normalized ratio; PE: Pulmonary embolism; VTE: Venous thromboembolic; ACCP: American College of Chest Physician; UFH: Unfractionated heparin; LMWH: Lower molecular weight heparin.

Funding: None

\section{CONFLICT OF INTEREST}

None declared

\section{ACKNOWLEDGEMENT}

The authors would like to acknowledge the patients, clinicians and staff of Civil hospital.

Ethical approval: The study was approved by Institutional Ethics committee.

\section{REFERENCES}

1. Spencer FA, Emery C, Lessard D, Anderson F, Emani S, Aragam J, et al. The Worcester venous thromboembolism study: A population based study of the clinical epidemiology of venous thromboembolism. J Gen Intern Med. 2006;21(7):722-7.

2. Anderson FA Jr., Wheeler HB, Goldberg RJ, Hosmer DW, Patwardhan NA, Jovanovic $B$, et al. A population based perspective of the hospital incidence and case-fatality rates of deep vein thrombosis and pulmonary embolism. The Worcester DVT Study. Arch Intern Med. 1991;151:933-8.

3. Dhillon KS, Askander A, Doraismay S. Postoperative deep-vein thrombosis in Asian patients is not a rarity: A prospective study of 88 patients with no prophylaxis. J Bone Joint Surg Br. 1996;78:427-30.

4. Lee LH, Gu KQ, Heng D. Deep vein thrombosis is not rare in Asia--the Singapore General Hospital experience. Ann Acad Med Singapore. 2002;31(6):761-4.

5. Kearon C, Kahn SR, Agnelli G, Goldhaber S, Raskob GE, Comerota AJ. American College of Chest Physicians. Antithrombotic therapy for venous thromboembolic disease: American College of Chest Physicians Evidence-Based Clinical
Practice Guidelines (8 $8^{\text {th }}$ Edition). Chest. 2008;133(6 Suppl):454S-545S

6. Bates SM, Ginsberg JS. Clinical practice. Treatment of deep-vein thrombosis. N Engl J Med. 2004;351:268-77.

7. Snow V, Qaseem A, Barry P, Hornbake ER, Rodnick JE, Tobolic T, et al. Management of venous thromboembolism: A clinical practice guideline from the American College of Physicians and the American Academy of Family Physicians. Ann Intern Med. 2007;146(3):204-10.

8. Dolovich LR, Ginsberg JS, Douketis JD, Holbrook AM, Cheah G. A meta-analysis comparing low-molecular-weight heparins with unfractionated heparin in the treatment of venous thromboembolism: Examining some unanswered questions regarding location of treatment, product type, and dosing frequency. Arch Intern Med. 2000;160(2):181-8.

9. Kearon C, Ginsberg JS, Julian JA, Douketis J, Solymoss S, Ockelford P, et al. Comparison of fixed dose weight adjusted unfractionated heparin and low molecular weight heparin for acute treatment of venous thromboembolism. JAMA. 2006;296(8):935-42.

10. Geerts WH, Pineo GF, Heit JA, et al. Prevention of venous thromboembolism: the Seventh ACCP Conference on Antithrombotic and Thrombolytic Therapy. Chest. 2004;126:338-400

11. Hill J, Treasure T. Reducing the risk of venous thromboembolism in patients admitted to hospital: summary of NICE guidance. BMJ. 2010;340:c95.

12. Soumerai SB, McLaughlin TJ and Avorn J. Improving drug prescribing in primary care: a critical analysis of the experimental literature. Milbank. 1989;67:268-317.

13. Rational Pharmaceutical Management Plus Program. Identifying Problems with Drug Use. In: Drugs and Therapeutics Committee Training Course [serial on the Internet] Management Sciences for Health, Arlington, VA. [cited 2007 May 26]. Available from: URL: http://www1.msh.org/ projects/rpmplus/Documents/upload/DTC-Training-Course-Session-7.pdf.

14. Lee AD, Stephen E, Agarwal S. Venous thromboembolism in India. Eur J vasc Endovasc Surg. 2008;37:482-85.

15. Cohen AT, Davidson BL, Gallus AS. Efficacy and safety of fondaparinux for the prevention of venous thromboembolism. BMJ. 2013;332:325-29.

16. $\mathrm{Ng} \mathrm{H}$, Quek S, Lee LH. Pattern of cases and impact of venous thromboembolism in a tertiary institution defying notions of VTE as a disorder of lower significance among Asians. J Thromb Haemost. 2003;1(suppl. 1).

17. Tripathi KD. Essentials of Medical Pharmacology. $6^{\text {th }}$ edition. New Delhi: Jaypee Brothers Medical Publishers (P) LTD; 2008:p. 593-611.

18. Lassen MR, Raskob GE, Gallus A et al. Epixaban or Enoxaparin for thromboprophylaxis after knee replacement. New eng J Med. 2009;361(6);594-604.

19. Van Dongen CJ, Van Den Bel AG, Prins MH et al. Fixed dose subcutaneous low molecular weight heparins versus adjusted dose unfractionated heparin for venous thromboembolism. Cochrane database syst Rev. 2004;18(4):CD001100.

20. Lip GY, Frison L, Halperin JL, Lane DA. Comparative validation of a novel risk score for predicting bleeding risk in anticoagulated patients: The HAS-BLED score (Hypertension, abnormal renal/liver function, stroke, bleeding history or predisposition, labile INR, elderly, drugs/alcohol concomitantly). J Am Coll Cardiol. $2011 ; 57(2): 173-80$

21. Heit JA, Silverstein MD, Mohr DN, Petterson TM, O'Fallon WM, Melton LJ $3^{\text {rd }}$ Risk factors for deep vein thrombosis and pulmonary embolism: a populationbased case-control study. Arch Intern Med. 2000;160(6):809-15.

22. Hansson PO, Eriksson H, Welin L, Svardsudd K, Wilhelmsen L. Smoking and abdominal obesity: risk factors for venous thromboembolism among middleaged men: "the study of men born in 1913... Arch Intern Med. 2000;159(16):1886-90.

23. Mohr DN, Silvester MD, Heit JA. The venous stasis syndrome after deep vein thrombosis or pulmonary embolism; a population based study. Mayo Clin Proc. 2000;75(12):1249-56.

24. Otero R, Uresandi F, Cayuela A. Use of venous thromboembolism prophylaxis for surgical patients: A multicentre analysis of practice. Eur J Surg. $2001 ; 167(3): 163-67$.

Article History: Submission Date : 10-10-2017 ; Revised Date : 02-11-2017; Acceptance Date : 25-11-2017.

Cite this article: Dumatar CB, Jadav SS, Patel AJ. Antithrombotic Utilization Evaluation in Patients Suffering from Deep Vein Thrombosis at a Tertiary Care Teaching Hospital. JYoung Pharm. 2018;10(1):82-5. 